\title{
Association of HLA-DRB alleles and pulmonary tuberculosis in North Chinese patients
}

\author{
G.L. Shi, X.L. Hu, L. Yang, C.L. Rong, Y.L. Guo and C.X. Song \\ Department of Clinical Immunology Laboratory, \\ Beijing Tuberculosis and Thoracic Tumor Research Institute, Beijing, P.R. China \\ Corresponding author: G.L. Shi \\ E-mail: shiguangli878@sina.com
}

Genet. Mol. Res. 10 (3): 1331-1336 (2011)

Received November 3, 2010

Accepted December 20, 2010

Published July 5, 2011

DOI 10.4238/vol10-3gmr1132

\begin{abstract}
Human leukocyte antigen (HLA) plays a central role in the regulation of the immune response. HLA class II molecules are essential for $\mathrm{T}$ cell-mediated adaptive immunity and present peptide antigens to $\mathrm{CD}^{+} \mathrm{T}$ cells. Because of its important role in the immune response and its high degree of polymorphism, the HLA system is associated with many diseases. We examined the polymorphisms of HLA-DRB alleles and the sequences of the HLA-DRB promoter region in 97 unrelated patients with pulmonary tuberculosis and in 62 unrelated normal controls of the Han nationality from North China, using PCR with sequence-specific primers and PCR direct sequencing. We found that the frequency of HLA-DRB ${ }^{*} 15$ was significantly higher in the pulmonary tuberculosis group than in the healthy control group. The $\mathrm{P}$ value was 0.001 , and the odds ratio was 3.793 . The pulmonary tuberculosis group had the same HLA-DRB1 promoter region sequences as the control group. We concluded that the HLA-DRB $1 * 15$ allele is associated with pulmonary tuberculosis in the Han nationality from North China. The HLA-DRB1 promoter region sequences had no association with the development of pulmonary tuberculosis.
\end{abstract}

Key words: Pulmonary tuberculosis; Human leukocyte antigen; Gene frequency; Promoter 


\section{INTRODUCTION}

Tuberculosis is a serious health problem with an estimated 8-10 million new cases per year worldwide, resulting in 1-2 million deaths every year (Harfouch-Hammoud and Daher, 2008). The population in China still faces a high burden of tuberculosis in China. Tuberculosis is a chronic infectious disease, which is mainly caused by Mycobacterium tuberculosis. It is estimated that approximately one-third of the world's population is infected with Mycobacterium tuberculosis, but only $10 \%$ of those infected by the mycobacterium will develop a clinical disease, which indicates the existence of host factors regulating disease expression (Bellamy and Hill, 1998). In addition, twin studies show an increased concordance rate among monozygotic compared to dizygotic twins, indicating the important role of host genetic factors in the development of tuberculosis (Kallman and Reisner, 1943; Comstock, 1978).

The human leukocyte antigen (HLA) system is the major histocompatibility complex in humans. The primary function of the HLA system is to regulate the immune response (Bjorkman et al., 1987). HLA-II molecules bind antigen peptides and present them to T cells, which then differentiate into cytotoxic or helper T cells by recognition of the antigen peptide-HLA complexes (Klein and Sato, 2000). As one of the host genetic factors, an association of HLA with susceptibility to tuberculosis has been studied in many ethnic groups, but the results are conflicting. HLA studies have revealed that the allele DRB1*15 is associated with tuberculosis in Indians (Sriram et al., 2001), DRB1*12 in Indonesians (Yuliwulandari et al., 2010), DRB1*13 in Polish (Dubaniewicz et al., 2000), DRB1*14 in Iranians (Mahmoudzadeh-Niknam et al., 2003), and DRB1*1302 in South Africans (Lombard et al., 2006). DRB $1 * 0803$ and DQB1*0601 were associated with tuberculosis disease progression in Koreans (Kim et al., 2005). The promoter region of HLA-II genes also shows polymorphism, such as in the X-box and Y-box. The polymorphism of the promoter region is associated with many diseases and controls the level of expression of HLA-II genes (Singal and Qiu, 1996; Louis-Plence et al., 2000).

In this study, we examined the polymorphisms of HLA-DRB alleles and the sequences of the HLA-DRB1 promoter region in 97 unrelated patients with pulmonary tuberculosis (PTB) and in 62 unrelated normal controls of Han nationality from North China, using polymerase chain reaction (PCR) amplification with sequence-specific primer (SSP) and PCR direct sequencing. Our purpose in this study was to investigate the association of HLA-DRB alleles and HLA-DRB1 promoter region polymorphisms with PTB in China.

\section{MATERIAL AND METHODS}

\section{Subjects}

The study used a case-control design to compare healthy controls and PTB patients. A total of 97 unrelated patients with PTB of Han nationality from North China were enrolled at the Respiratory Department of the Beijing Tuberculosis Research Institute. The subjects ranged in age from 19 to 61 years, with a mean age of 43.1 years, and 51 of them were males and 46 females. The diagnoses were confirmed by the cultivation of Mycobacterium tuberculosis in sputum culture with or without the presence of acid-fast bacilli in sputum smear and by standard clinical and radiologic investigations. Only patients who were shown to be HIV-negative by clinics were included in the study. A control group composed of 62 ethnically matched, unrelated individuals were also included in the analyses. 


\section{HLA DNA typing and DNA direct sequencing}

Genomic DNA from patients and controls was extracted by standard techniques from peripheral blood leukocytes (Davis et al., 1980; Miller et al., 1988). DNA was typed using the SSP typing kit (purchased from Institute of Basic Medical Sciences in Beijing), following manufacturer instructions. DNA direct sequencing of the HLA-DRB1 promoter region was carried out by Beijing Huada Biotechnology Company.

\section{Statistical analysis}

Phenotype frequencies of the HLA-DRB alleles were compared by the $\chi^{2}$ test or the Fisher exact test as appropriate, using the SPSS program, version 13.0. The level of significance was set at $\mathrm{P}<0.05$, and the odds ratio (OR) with 95\% confidence interval (CI) was calculated for those comparisons showing significant $P$ values.

\section{RESULTS}

\section{Alleles of HLA-DRB in PTB patients and controls}

The distribution of HLA-DRB alleles in PTB patients and controls is illustrated in Table 1, where a significant increase in DRB $1 * 15$ allele frequency in PTB patients compared to controls was observed $(\mathrm{OR}=3.793, \mathrm{P}=0.001)$. The other HLA-DRB alleles were similarly distributed in patients and controls.

\begin{tabular}{|c|c|c|c|c|}
\hline \multirow[t]{2}{*}{ Allele } & Frequency in controls & Frequency in patients & \multirow[t]{2}{*}{ OR $(95 \% \mathrm{CI})$} & \multirow[t]{2}{*}{$\mathrm{P}$} \\
\hline & $(\mathrm{N}=62)(\%)$ & $(\mathrm{N}=97)(\%)$ & & \\
\hline DRB $1 * 01$ & $2(3.22 \%)$ & $4(4.12 \%)$ & \multirow{16}{*}{$3.793(2.196-6.543)$} & 0.771 \\
\hline DRB1*15 & $9(14.5 \%)$ & $38(39.2 \%)$ & & 0.001 \\
\hline DRB $1 * 16$ & $3(4.84 \%)$ & $7(7.21 \%)$ & & 0.394 \\
\hline DRB $1 * 03$ & $2(3.22 \%)$ & $3(3.09 \%)$ & & 1.000 \\
\hline DRB $1 * 11$ & $10(16.1 \%)$ & $15(15.5 \%)$ & & 0.874 \\
\hline DRB $1 * 12$ & $12(19.3 \%)$ & $19(19.6 \%)$ & & 0.959 \\
\hline DRB1*06 & $3(4.84 \%)$ & $3(3.09 \%)$ & & 0.548 \\
\hline DRB $1 * 13$ & $5(8.06 \%)$ & $7(7.21 \%)$ & & 0.780 \\
\hline DRB $1 * 14$ & $4(6.45 \%)$ & $5(5.15 \%)$ & & 0.652 \\
\hline DRB $1 * 07$ & $14(22.5 \%)$ & $18(18.6 \%)$ & & 0.383 \\
\hline DRB $1 * 08$ & $9(14.5 \%)$ & $15(15.5 \%)$ & & 0.818 \\
\hline DRB $1 * 09$ & $11(17.7 \%)$ & $19(19.6 \%)$ & & 0.682 \\
\hline DRB $1 * 10$ & $3(4.84 \%)$ & $3(3.09 \%)$ & & 0.548 \\
\hline DRB3 & $35(56.4 \%)$ & $49(50.5 \%)$ & & 0.301 \\
\hline DRB4 & $32(51.6 \%)$ & $58(59.8 \%)$ & & 0.151 \\
\hline DRB5 & $24(38.7 \%)$ & $36(37.1 \%)$ & & 0.775 \\
\hline
\end{tabular}

Data are reported as number with percent in parentheses.

\section{The sequences of HLA-DRB1 promoter region in PTB patients and controls}

The result of DNA direct sequencing of the HLA-DRB1 promoter region showed that the pulmonary tuberculosis group had the same HLA-DRB1 promoter sequences as the control group. The sequences of the HLA-DRB1 promoter region are illustrated in Figure 1. 


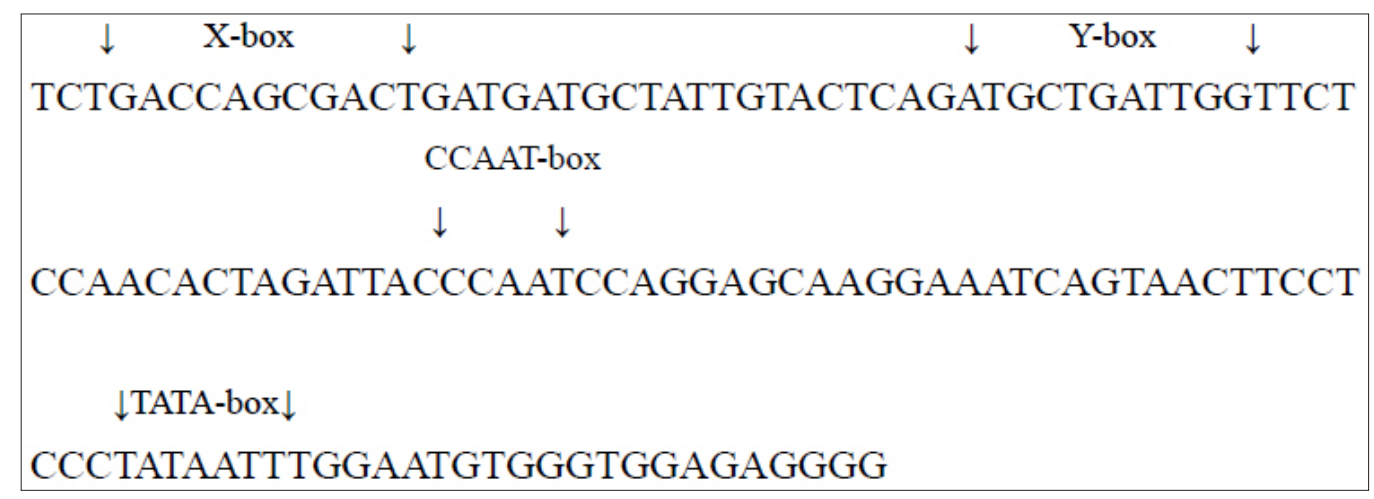

Figure 1. The sequences of HLA-DRB1 promoter region in controls and patients with pulmonary tuberculosis.

\section{DISCUSSION}

Associations between HLA and susceptibility to diseases have been reported for more than 500 diseases, including PTB. The aim of this study was to analyze the association of HLA-DRB alleles and HLA-DRB1 promoter region polymorphisms with PTB in the Han population of North China.

We found that the frequency of the HLA-DRB $1 * 15$ allele was higher in patients with PTB for the Han nationality of North China $(14.5$ vs $39.2 \%, \mathrm{P}=0.001, \mathrm{OR}=3.793,95 \% \mathrm{CI}=$ 2.196-6.543). HLA-DRB1*15 has been reported in many ethnic groups to be the main HLA allele associated with susceptibility, such as in the Indian population (Ravikumar et al., 1999; Sriram et al., 2001) and in the Mexican population (Teran-Escandon et al., 1999). Some results of other studies were different from ours, such as DRB $1 * 12$ in the Indonesian population (Yuliwulandari et al., 2010), DRB1*13 in the Polish population (Dubaniewicz et al., 2000), DRB1*14 in the Iranian population (Mahmoudzadeh-Niknam et al., 2003), and DRB1*1302 in the South African population (Lombard et al., 2006). The difference in HLA-DRB alleles between various populations can be explained partly by variation in the technique used, small sample size, and linkage disequilibrium. There are many molecular techniques used for typing HLA genes, including PCR-restriction fragment length polymorphism (Bidwell et al., 1988), PCR-SSP (Olerup and Zetterquist, 1992), PCR-single strand conformation polymorphism (Ainsworth et al., 1991; Young and Darke, 1993), PCR-sequence specific oligonucleotide probes (Dalva and Beksac, 2007), and sequencing-based typing (Hoppe and Salama, 2007). In this study, we used the PCR-SSP technique to type HLA alleles. Our studies showed that the DRB1*15 allele was associated with PTB susceptibility in the Han nationality of North China. However, there is still another possibility that other genes closely linked to the HLA-DRB*15 allele are primarily associated with PTB susceptibility.

We also determined the amino acid sequences of HLA-DRB1 promoter region, because they can control the level of expression of HLA-II genes. The results showed that there were no differences in HLA-DRB1 promoter sequences between PTB patients and controls. This finding has not been previously reported.

PTB is a complex disease resulting from multiple interactions between genetic and environmental factors. The molecular mechanism of association between HLA and PTB may be 
that HLA molecules bind antigen peptides and present them to T cells, which then differentiate into cytotoxic or helper T cells by recognition of the antigen peptide-HLA complexes. CD4 T cells, CD8 T cells and CD1-restricted T cells participate in the immune response to Mycobacterium tuberculosis, among which CD4 T cells play a major role in containing PTB at all stages of the disease. CD4 T cells recognize antigenic peptides in the context of HLA class II molecules, and thus, particular HLA class II alleles may not be able to present appropriate antigenic peptides of tubercle bacilli to CD4 T cells (Kaufmann, 2002; Ulrichs and Kaufmann, 2004).

In summary, we studied the association between HLA-DRB and PTB. Our results suggest that the HLA-DRB*15 allele is associated with PTB susceptibility in the Han nationality of North China and that the polymorphisms of HLA-DRB1 promoter sequences are not associated with PTB susceptibility. However, because of the relatively small number of patients and the possibility of racial differences, further investigation using a larger sample size to confirm the present findings is necessary.

\section{ACKOWLEDGMENTS}

We are grateful to patients and controls who took part in this investigation. Research supported by Beijing Tuberculosis and Thoracic Tumor Research Institute.

\section{REFERENCES}

Ainsworth PJ, Surh LC and Coulter-Mackie MB (1991). Diagnostic single strand conformational polymorphism, (SSCP): a simplified non-radioisotopic method as applied to a Tay-Sachs B1 variant. Nucleic Acids Res. 19: 405-406.

Bellamy R and Hill AV (1998). Genetic susceptibility to mycobacteria and other infectious pathogens in humans. Curr. Opin. Immunol. 10: 483-487.

Bidwell JL, Bidwell EA, Savage DA, Middleton D, et al. (1988). A DNA-RFLP typing system that positively identifies serologically well-defined and ill-defined HLA-DR and DQ alleles, including DRw10. Transplantation 45: 640-646.

Bjorkman PJ, Saper MA, Samraoui B, Bennett WS, et al. (1987). The foreign antigen binding site and T cell recognition regions of class I histocompatibility antigens. Nature 329: 512-518.

Comstock GW (1978). Tuberculosis in twins: a re-analysis of the Prophit survey. Am. Rev. Respir. Dis. 117: 621-624.

Dalva K and Beksac M (2007). HLA typing with sequence-specific oligonucleotide primed PCR (PCR-SSO) and use of the Luminex technology. Methods Mol. Med. 134: 61-69.

Davis RW, Thomas M, Cameron J, St John TP, et al. (1980). Rapid DNA isolations for enzymatic and hybridization analysis. Methods Enzymol. 65: 404-411.

Dubaniewicz A, Lewko B, Moszkowska G, Zamorska B, et al. (2000). Molecular subtypes of the HLA-DR antigens in pulmonary tuberculosis. Int. J. Infect. Dis. 4: 129-133.

Harfouch-Hammoud EI and Daher NA (2008). Susceptibility to and severity of tuberculosis is genetically controlled by human leukocyte antigens. Saudi Med. J. 29: 1625-1629.

Hoppe B and Salama A (2007). Sequencing-based typing of HLA. Methods Mol. Med. 134: 71-80.

Kallman FJ and Reisner D (1943). Twin studies on the significance of genetic factors in tuberculosis. Am. Rev. Tuberc. 47: 549-574.

Kaufmann SH (2002). Protection against tuberculosis: cytokines, T cells, and macrophages. Ann. Rheum. Dis. 61 (Suppl 2): ii54-ii58.

Kim HS, Park MH, Song EY, Park H, et al. (2005). Association of HLA-DR and HLA-DQ genes with susceptibility to pulmonary tuberculosis in Koreans: preliminary evidence of associations with drug resistance, disease severity, and disease recurrence. Hum. Immunol. 66: 1074-1081.

Klein J and Sato A (2000). The HLA system. First of two parts. N. Engl. J. Med 343: 702-709.

Lombard Z, Dalton DL, Venter PA, Williams RC, et al. (2006). Association of HLA-DR, -DQ and vitamin D receptor alleles and haplotypes with tuberculosis in the Venda of South Africa. Hum. Immunol. 67: 643-654.

Louis-Plence P, Kerlan-Candon S, Morel J, Combe B, et al. (2000). The down-regulation of HLA-DM gene expression in rheumatoid arthritis is not related to their promoter polymorphism. J. Immunol. 165: 4861-4869. 
Mahmoudzadeh-Niknam H, Khalili G and Fadavi P (2003). Allelic distribution of human leukocyte antigen in Iranian patients with pulmonary tuberculosis. Hum. Immunol. 64: 124-129.

Miller SA, Dykes DD and Polesky HF (1988). A simple salting out procedure for extracting DNA from human nucleated cells. Nucleic Acids Res. 16: 1215.

Olerup O and Zetterquist H (1992). HLA-DR typing by PCR amplification with sequence-specific primers (PCR-SSP) in 2 hours: an alternative to serological DR typing in clinical practice including donor-recipient matching in cadaveric transplantation. Tissue Antigens 39: 225-235.

Ravikumar M, Dheenadhayalan V, Rajaram K, Lakshmi SS, et al. (1999). Associations of HLA-DRB1, DQB1 and DPB1 alleles with pulmonary tuberculosis in south India. Tuber. Lung Dis. 79: 309-317.

Singal DP and Qiu X (1996). Polymorphism in both X and Y box motifs controls level of expression of HLA-DRB1 genes. Immunogenetics 43: 50-56.

Sriram U, Selvaraj P, Kurian SM, Reetha AM, et al. (2001). HLA-DR2 subtypes \& immune responses in pulmonary tuberculosis. Indian J. Med. Res. 113: 117-124.

Teran-Escandon D, Teran-Ortiz L, Camarena-Olvera A, Gonzalez-Avila G, et al. (1999). Human leukocyte antigenassociated susceptibility to pulmonary tuberculosis: molecular analysis of class II alleles by DNA amplification and oligonucleotide hybridization in Mexican patients. Chest 115: 428-433.

Ulrichs T and Kaufmann SH (2004). Cell-Mediated Immune Response. 2nd edn. In: Tuberculosis (Rom WN and Garay SM, eds.). Lippincott Williams \& Wilkins, Philadelphia.

Young NT and Darke C (1993). Allelic typing of the HLA-DR4 group by polymerase chain reaction-single-strand conformation polymorphism analysis. Hum. Immunol. 37: 69-74.

Yuliwulandari R, Sachrowardi Q, Nakajima H, Kashiwase K, et al. (2010). Association of HLA-A, -B, and -DRB1 with pulmonary tuberculosis in western Javanese Indonesia. Hum. Immunol. 71: 697-701. 